\title{
Antibodies in Serum of Patients with Alzheimer's Disease Cause Immunolysis of Cholinergic Nerve Terminals from the Rat Cerebral Cortex
}

\author{
H.F. Bradford, P. Foley, M. Docherty, H. Fillit, V.N. Luine, B. McEwen, \\ G. Bucht, B. Winbald and J. Hardy
}

\begin{abstract}
A blind study showing that serum from patients with Alzheimer's disease causes immunolysis of mammalian brain synaptosomes is reported. Control, aged-matched, sera were largely without effect. The immunolysis was directed mainly against cholinergic synaptosomes. The data support the hypothesis that autoimmune mechanisms may operate in the pathogenesis of Alzheimer's disease.
\end{abstract}

RÉSUMÉ: Des anticorps présents dans le sérum de patients atteints de la maladie d'Alzheimer causent une immunolyse des terminaisons nerveuses cholinergiques dans le cortex cérébral du rat Nous rapportons une étude en aveugle montrant que le sérum de patients atteints de la maladie d'Alzheimer cause une immunolyse des synaptosomes du cerveau chez les mammifères. Des sérums témoins, appariés pour l'âge, étaient essentiellement inefficaces. L'immunolyse était dirigée surtout contre les synaptosomes cholinergiques. Ces données supportent l'hypothèse que des mécanismes autoimmuns peuvent opérer dans la pathogénèse de la maladie d'Alzheimer.

Can. J. Neurol. Sci. 1989; $16: 528-534$

Various hypotheses have been proposed to explain the progression of the pathology seen in Alzheimer's disease (AD).1,2 However, to date no single hypothesis encompasses all known changes. Changes in a range of neurotransmitter systems have been reported including acetylcholine, ${ }^{3}$ somatostatin ${ }^{4}$ and glutamate. ${ }^{5-7}$ The failure in the cholinergic system has been a main focus of interest, and this is linked to an observed loss of neurons in the basal forebrain and of cholinergic markers in the cerebral cortex of postmortem brains, 1,3,8-10

The presence of amyloid fibrils containing IgG and sometimes complement in cortical plaques in post mortem brain tissue has suggested a link between autoimmune responses and the pathogenesis of the disease. ${ }^{2,11} \mathrm{~A}$ bloodbrain barrier deficit has been reported in many cases, 10,12 and amyloid deposits and neuritic plaques are often found associated with blood vessels. Moreover, antibodies inhibiting choline acetyltransferase (ChAT) activity and specifically binding to cholinergic neurons, have been reported in sera from patients with $A D^{13-16}$ and these observations have raised the question of whether autoimmune factors might play a part in the pathogenesis of the disease. ${ }^{2}$ An autoimmune reaction directed at cholinergic neurons in the brain was proposed by Fillit et al. 14 They found that serum from some patients with $\mathrm{AD}$ contained IgG which reacted with large magnocellular neurons in the rat and human basal forebrain. These neurons were similar in size and distribution to the large cholinergic cells which can be demonstrated in the normal basal forebrain by anti-ChAT staining. These are neurons which are lost in patients with AD. ${ }^{14}$ Another group using an immunocytochemical approach has reported the presence in the cerebrospinal fluid (CSF) from patients with AD of antibodies which recognise specifically cholinergic neurons in rat CNS sections. ${ }^{16}$ Similarly, antibodies to cholinergic neurons of the electric fish Torpedo have been detected in the serum of patients with AD using immunoblotting and ELISA assays. ${ }^{17,18}$ We have reported the presence in sera from groups of American and Swedish patients with $\mathrm{AD}$ of antibodies which are able to lyse incubated mammalian brain synaptosomes in the presence of complement. 19,20 This immunolysis phenomenon is detected by the release of the

From the Departments of Biochemistry, Imperial College of Science and Technology (HFB, PF and MD) and St. Mary's Hospital Medical School (JH), London, Rockefeller University, New York (HF, VNL and BM), and the Departments of Geriatric Medicine, University of Umea (GB) and Karolinska Institute (BW), Sweden

Reprint requests to: Professor H.F. Bradford, Department of Biochemistry, Imperial College of Science and Technology, London SW7 2AZ UK 
soluble cytolasmic enzymes, lactate dehyrogenase (LDH) and ChAT, from the synaptosomes into the incubation fluid, and by diminished ability to accumulate choline by high affinity transport. ${ }^{21}$ Immunolysis can only occur when the antibodies present recognise and bind to an antigen on the outer cell surface, thereby triggering the complement-mediated lytic action. The findings are discussed in terms of the significance of autoimmune factors in the pathogenesis of AD.

\section{Methods}

\section{Serum from Patients with Alzheimer's Disease and Controls}

\section{American patients and controls}

All patients met NINCDS-ADRDA criteria for the clinical diagnosis of probable AD.22 The patients and controls were rated for clinical severity employing the clinical rating scale of Reisberg et al, ${ }^{23}$ and controls were age matched to the patients. All patients were of severity greater than 4 on the Reisberg scale which has the range 1-7. This scale correlates well with the mini-mental scale ${ }^{17,24}$ used for the Swedish patients. The age range was 52 to 88 years for the 10 patients (mean age $72.3 \pm 3.8$ years, the median age was 76 years). The duration of the illness at the time of blood sampling was $3.5 \pm 0.8$ years with a median duration of 2.5 years. Controls were healthy, elderly volunteers (over 65 years old) and in the cognitive tests they all scored 1 on the Reisberg scale.

\section{Swedish patients and controls}

The patients with $A D$ were all diagnosed after an exhaustive clinical evaluation using the DSM III criteria, ${ }^{25}$ and were all of high severity (mini-mental state score less than 17 on a scale 0 $30^{24}$ ).

The age range was 58 to 88 years (mean age $73 \pm 3.3$ years, the median age was 71.5 years for the 8 patients). The duration of the illness at the time of blood sampling was $6.6 \pm 1.2$ years with a median duration of 6 years. Controls were aged matched to the patients and were also tested using the DSM III criteria. They showed mini-mental state scores greater than 25 .

\section{Immunolysis Test}

This was based on the method of Docherty et al ${ }^{21}$ One $\mathrm{ml}$ of synaptosomes prepared from cerebral cortex of Sprague Dawley rats ${ }^{26}$ was pre-incubated (approx $1 \mathrm{mg}$ synaptosomal protein $/ \mathrm{ml}$ ) at $37^{\circ} \mathrm{C}$ in oxygenated phosphate-buffered Krebs-glucose medium (mM); $\mathrm{NaCl}, 140 ; \mathrm{KCl}, 4.0 ; \mathrm{MgCl}_{2}, 1.6 ; \mathrm{CaCl}_{2}, 1.0$; $\mathrm{Na}_{2} \mathrm{HPO}_{4} / \mathrm{NaH}_{2} \mathrm{PO}_{4}, 20.0$; glucose, 20.0 for 15 min before addition of serum alone, guinea-pig complement alone, or serum plus complement. Incubations were continued for $60 \mathrm{~min}$, except where the time course was studied. Synaptosomes were then deposited by centrifugation $(10,000 \mathrm{~g} / 30 \mathrm{sec})$ and supernatants were decanted. The tissue fraction was resuspended and used to test levels of $\mathrm{Na}$-dependent high-affinity choline uptake. The levels of ChAT and LDH were measured in the supernatant fraction.

Control and patient sera were treated identically throughout. Serum samples with added azide $(0.02 \% \mathrm{w} / \mathrm{v})$ were stored at 0 $4^{\circ} \mathrm{C}$. Both serum samples and complement were dialysed against incubation medium $(2 \times 1000 \mathrm{vol}$.) for $3 \mathrm{~h}$ under vacuum dialysis before use. Typically $100 \mu \mathrm{l}$ of serum sample and $50 \mu \mathrm{l}$ of guinea pig complement were added to $850 \mu \mathrm{l}$ of synaptosome suspension. 50 to $200 \mu \mathrm{l}$ of serum were used in dose response studies. No LDH or ChAT activity was detected in any of the serum samples. ChAT was measured by the method of Fonnum ${ }^{27}$ and LDH by the method of Vassault. ${ }^{28}$ Glutamate decarboxylase (GAD) and high-affinity choline transport were measured by the methods of Docherty et al ${ }^{21}$ and dopamine- $\beta$ hydroxylase (DBH) by the method of Joh et al. ${ }^{29}$

All patients' sera were tested interspersed with control sera, one control and one (or more) serum from a patient with $A D$ being tested together.

Beyond this pairing, all the tests were made blind in each series (i.e. the sera were not identified as being control or patient in origin). In each test series a triplicate set of "no addition" controls was also run, these contained neither control nor patients' sera. They acted as controls for the serum or complement alone additions.

The difference between paired patient and control sera tested against a particular synaptosome preparation was selected as the index of lysis.

The immunolysis test was found to be reproducible; a given serum produced the same degree of immunolysis when tested on separate occasions, even after several months storage at $0-4^{\circ} \mathrm{C}$. Triplicate samples gave very similar results.

\section{Statistics Employed}

The initial statistical analysis of the data summarized in Table 1 was performed by using a Biomedical Data Processing Program $8 \mathrm{~V}^{30}$ to do a mixed models analysis of variance with three between factors and one within factor with fixed and random levels respectively, employing each of the triplicate values in each analysis as a separate datum point. The analysis used the logarithms of each triplicate replication in the test groups as follows: (a) serum plus complement, (b) serum alone, (c) complement alone and (d) no addition, for both the AD patients' sera and control sera. The logarithms of the triplicates were normally distributed. This analysis indicated that working with logarithms stabilizes the variance and that none of the latter control conditions exerted a statistically significant effect on the parameters measured. The F-values generated by the program are given in Table 1.

\section{RESULTS}

\section{Basis for Immunolysis Test}

In the present study the possible presence in human sera of antibodies to cholinergic neurons was investigated by attempting to cause specific complement-mediated immunolysis of the cholinergic subpopulations present in incubated preparations of rat brain cerebrocortical synaptosomes. We have previously demonstrated such specific immunolysis of the cholinergic subpopulation of synaptosomes by the addition of antibodies which recognise $\mathrm{ChAT}$, together with complement, to incubated cerebrocortical or striatal synaptosome preparations. $21,31.32$ This demonstrates that ChAT, or a ChAT-like protein, is present in the nerve-terminal membrane and accessible at the outer surface (i.e. able to interact with ChAT antibodies), as well as existing largely as the freely soluble form in the cytoplasm. Good evidence now exists for the existence of ChAT in membranes. ${ }^{33-36}$ 
Lysis was monitored by following release of the soluble enzymes ChAT and LDH, and by measuring changes in the extent of high-affinity choline transport by the synaptosomes after exposure to dialysed serum with or without complement as described in Methods (Figure 1). Dose-response studies give a measure of the maximum possible release of enzymes or blockade of choline transport. The maximal release of LDH, expressed as a percentage of the total present, gives the approximate size of the cholinergic subpopulation (Figure 1).

In the extensive studies of Docherty et al,21,31,32 a maximum

Table 1: Summary of Data on ChAT and LDH Release and Choline Uptake Inhibition (See Figure 2)

\begin{tabular}{|c|c|c|c|}
\hline & ChAT Release & LDH Release & Choline Uptake \\
\hline $\begin{array}{l}\text { American Sera } \\
\text { Alzheimer (10) } \\
\text { Control }\end{array}$ & $\begin{array}{l}5.4 \pm 2.8 \\
0.2 \pm 1.1\end{array}$ & $\begin{array}{l}3.4 \pm 2.3 \\
0.5 \pm 0.3\end{array}$ & $\begin{array}{lr}(-) & 18.8 \pm 9.2 \\
(+) & 1.9 \pm 4.0\end{array}$ \\
\hline $\begin{array}{l}\text { Swedish Sera } \\
\text { Alzheimer (8) } \\
\text { Control } \quad(7)\end{array}$ & $\begin{array}{r}12.8 \pm 2.0 \\
3.3 \pm 2.1\end{array}$ & $\begin{array}{l}5.1 \pm 2.2 \\
1.1 \pm 1.0\end{array}$ & $\begin{array}{rr}(-) & 23.4 \pm 8.8 \\
(-) & 1.6 \pm 7.3\end{array}$ \\
\hline $\begin{array}{l}\text { Most active five Ame } \\
\text { and Swedish sera* } \\
\text { Alzheimer (10) } \\
\text { Control } \quad \text { (15) }\end{array}$ & $\begin{array}{r}13.8 \pm 2.1 \\
1.6 \pm 1.2\end{array}$ & $\begin{array}{l}5.1 \pm 2.0 \\
0.8 \pm 0.4\end{array}$ & $\begin{array}{l}\text { (-) } 26.05 \pm 9.3 \\
(+) \\
(+27 \pm 3.87\end{array}$ \\
\hline $\begin{array}{l}\text { "F" Values and Stati } \\
\text { All sera } \\
\text { American sera } \\
\text { Swedish sera } \\
\text { Five most active sera }\end{array}$ & $\begin{array}{rl}8.8 & \mathrm{p}<1 \% \\
4.88 & \mathrm{p}<2.5 \% \\
10.49 & \mathrm{p}<1 \% \\
7.34 & \mathrm{p}<2 \%\end{array}$ & $\begin{array}{ll}5.20 & p<2.5 \% \\
8.17 & p<1 \% \\
7.18 & p<1 \% \\
7.77 & p<2 \%\end{array}$ & $\begin{array}{rl}4.88 & \mathrm{p}<2.5 \% \\
8.88 & \mathrm{p}<1 \% \\
7.78 & \mathrm{p}<1 \% \\
10.20 & \mathrm{p}<2 \%\end{array}$ \\
\hline
\end{tabular}

Mean values \pm SEM are given for the number of sera given in parentheses. The individual data for each serum are shown in Figure 1.

"F" values were calculated by taking logarithms of the data in order to stabilize the variance.

* The potencies of the five most active American (sera 1 to 5) and Swedish (sera 1 to 5) AD sera (as judged by their ability to release ChAT) taken together were compared against all the controls). The analysis of variance data are for statistical analysis as described in Methods.

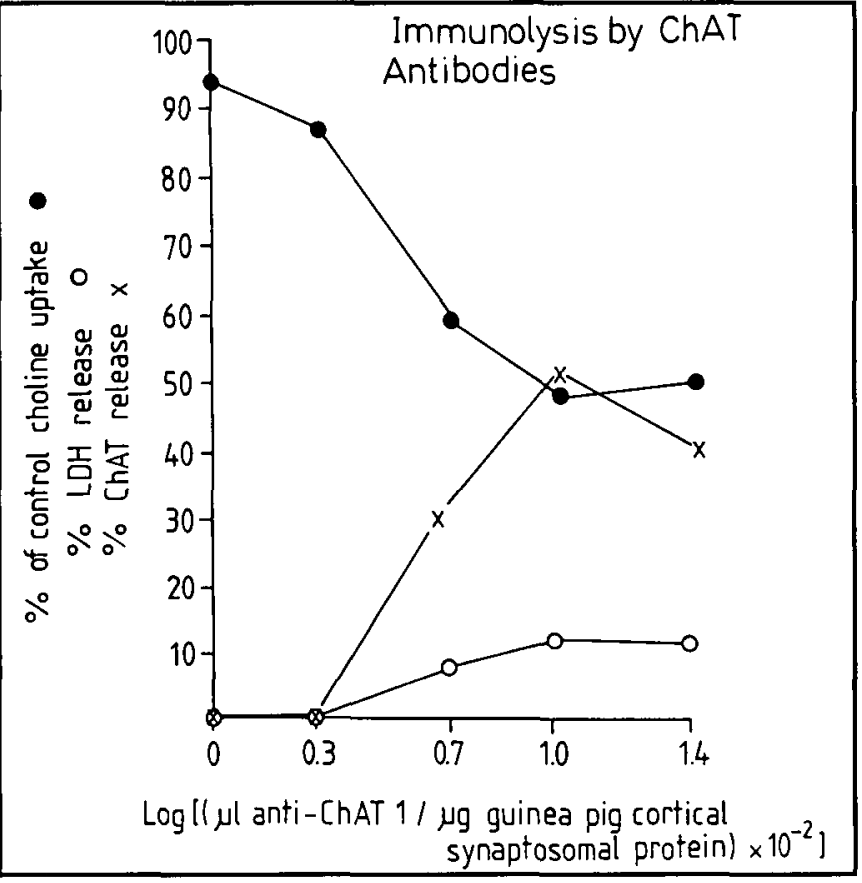

Figure $1(A)$ - Effects of antiserum against partially purified bovine ChAT (anti-ChAT I) plus complement, on synaptosomes prepared from guinea pig cerebral cortex. Values given represent the mean of triplicate observations on single synaptosome preparations, a total of 3 separate synaptosome preparations having been used. Control choline uptake was $5 \pm 2$ pmol/2 min-mg protein using $0.125 \mu \mathrm{M}$ choline. Untreated synaptosomes had a total LDH activity of $0.8 \pm 0.01 \mu \mathrm{mol} / \mathrm{min}-\mathrm{mg}$ protein (mean $\pm S . D ., n=3$ ) and a total ChAT activity of $1.2 \pm 0.2$ nmollmin-mg protein (mean $\pm S . D$., $n=3$ ). (Data from ref. 32 ).

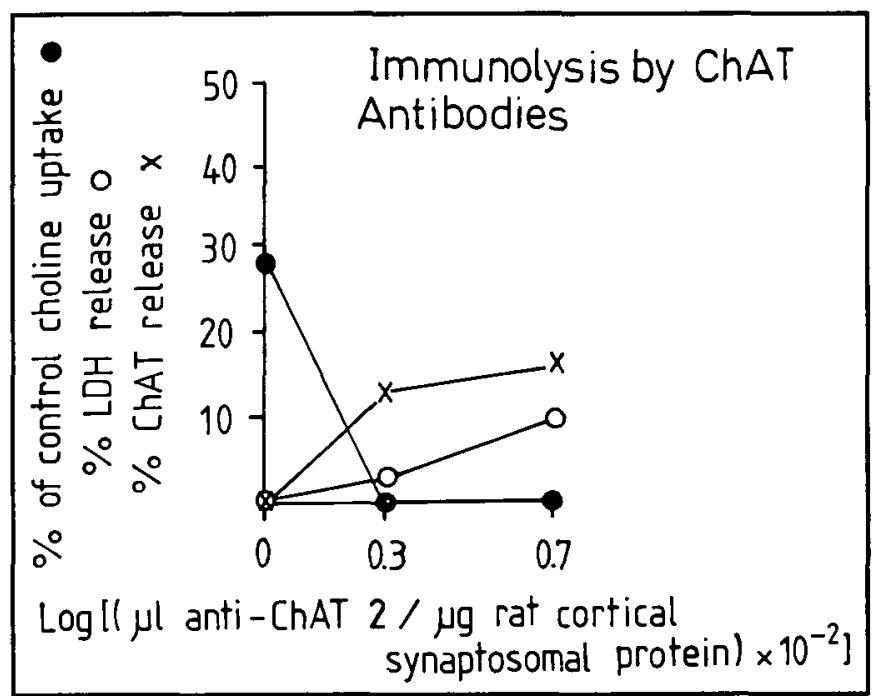

Figure $I(B)-$ Effects of antiserum against highly purified pig ChAT (ChAT 2), plus complement, on synaptosomes prepared from rat cerebral cortex. Values given represent the mean of triplicate observations on single synaptosome preparations, a total of 3 separate preparations having been used. Control choline uptake was $20 \pm 4$ pmol/2 min-mg protein using $0.125 \mu M$ choline (mean $\pm S . D$., $n=3$ ). Untreated synaptosomes had a total $L D H$ activity of $1.0 \pm 0.09 \mu$ mollmin-mg protein (mean $\pm S . D ., n-3)$ and total ChAT activity of $620 \pm 80$ pmoll/min-mg protein (mean $\pm S . D$., $n=3$ ). ChaT 2 was kindly provided by Prof. H. Thoenen of Max Planck Institute for Psychiatry, Martinsried, FRG. (Data from ref 32). 
of $10-15 \%$ of rat brain synaptosomes was immunolysed by antibodies to ChAT in the presence of complement, indicating that $10-15 \%$ of the whole synaptosome fraction is derived from cholinergic neurons (Figure 1). The figure was similar for synaptosomes from both cerebral cortex and corpus striatum of rat or guinea pig brain. ChAT antibodies from various animal sources had similar actions (Figure 1).21,32

\section{Action of Alzheimer and Control Sera}

Ten sera from American patients with AD were tested blind, randomly interspersed with 8 American control sera, and 8 Swedish patients with AD were similarly tested blind with 7 age-matched Swedish control sera. One control serum and one (or more) serum from a patient with $\mathrm{AD}$ were tested together against a particular batch of freshly prepared rat cerebrocortical synaptosomes. In these tests the action of serum plus complement was compared with that of complement alone. It can be seen from Figure 2 and Table 1 that the majority of sera from patients with AD caused greater release of ChAT and LDH into the incubation medium than the paired control with which it was tested. The difference between the mean values for ChAT or LDH release by grouped American AD patients or American control sera, without reference to pairing, also shows statistical- ly significant enhanced release of the enzymes to incubation medium (Table 1). High-affinity choline uptake was reduced by the majority of sera from American AD patients while the American control sera had little or no effect (Figure 2, Table 1).

The Swedish AD patients' sera resembled that from American AD cases in showing a similar tendency to release ChAT and LDH from rat cerebrocortical synaptosomes, and to reduce their high-affinity choline uptake, although there was more overlap with the action of control sera in the enzyme release (Figure 2). There was overall a significantly greater effect on each of the three parameters by the Swedish AD sera than by the paired Swedish control sera (Figure 2, Table 1). In both the Swedish and American series, sera from a few patients showed an apparent lytic action less than the matched control (e.g. pair 5 for LDH release in the American series). However, in these cases, the extent of release was very low for both the control and $\mathrm{AD}$ serum samples. Most of the latter individual sera were retested where supply allowed, and their mild lytic action was confirmed.

Essentially the same pattern of LDH and ChAT release, and depressed choline uptake, was obtained when differences between the addition of serum alone and serum plus complement (instead of complement alone and serum plus comple-

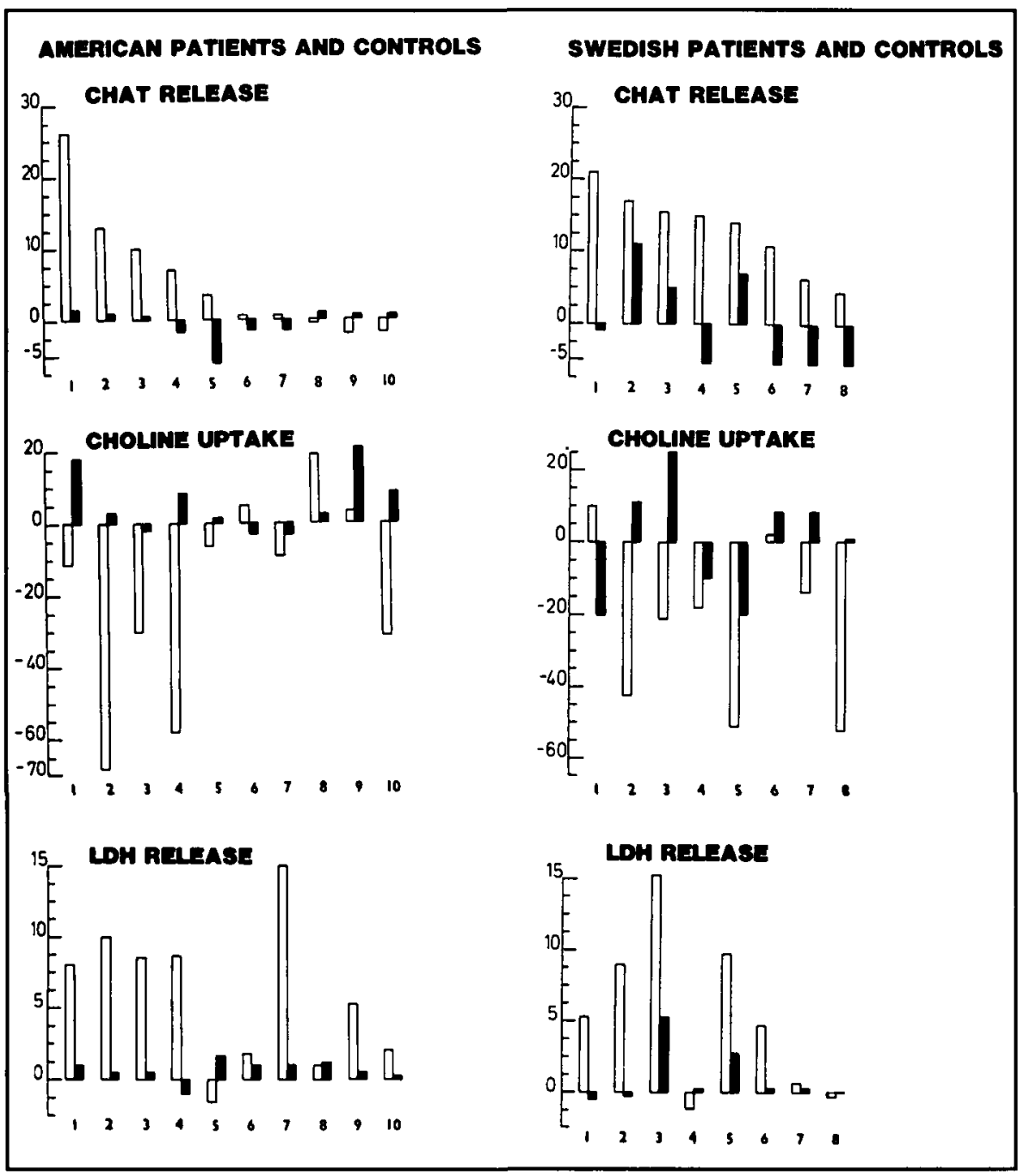

Figure 2-Action of Alzheimer and control sera plus complement on ChAT and $L D H$ release, and on high-affinity choline uptake into rat cerebrocortical synaptosomes. The action of patient $\square$ and paired control sera $\square$ are shown as histograms and assigned a number for identification in the other tests on this figure and in tests reported in Table 2. The ordinates for each parameter measured represent the difference between the action of serum plus complement and complement added alone to rat cerebrocortical synaptosomes expressed as a percentage of total enzyme present in the preparation which is released, or percentage of choline uptake in the absence of additions. For the enzymes, negative values indicate a larger action for complement alone in releasing the enzyme. For choline uptake, negative values indicate the degree of inhibition of the uptake process. The sera are arranged in a left to right sequence of increasing action of the $A D$ samples in causing release of ChAT. All tests were made blind, and one or more patients' sera were always tested with control sera against each synaptosome preparation. The choline uptake studies employed $1.0 \mu \mathrm{M}$ $\left({ }^{3} \mathrm{H}\right)$-choline $(I \mu \mathrm{C} / \mathrm{ml})$ to select high-affinity uprake. 
ment) were analysed for both American and Swedish sera. In this analysis of the data the differences in action between the two conditions were smaller by approximately $20 \%$. This was most likely due to the presence of residual active complement in some of the serum samples, because the sera were not heat-inactivated. It was for this reason that the details are given for serum plus complement as compared with complement alone, rather than for serum plus complement as compared with serum alone. Heat-treated sera were not used routinely, as there was an inhibitory effect (15\%) on choline transport by heated control sera when added alone.

\section{Specificity}

The action of the sera appeared to be specifically directed towards cholinergic synaptosomes. Thus, neither glutamate decarboxylase (GAD) nor dopamine-B-hydroxylase (DBH) were released in up to 2 hours of incubation with selected American or Swedish AD patients' sera which effectively released ChAT in the same test (Table 2). This indicates that neither GABAergic nor noradrenergic synaptosomes are lysed by these sera. Thus, the release of ChAT and reductions of high-affinity choline transport indicate specific immunolysis of cholinergic synaptosomes. It should be noted that complement or serum added alone produced relatively small effects (Table 2 ). These were commensurate with those produced in samples where no addition of complement or serum were made (data not shown).

\section{Correlation between Actions of Sera on the Three Parameters Measured}

The majority of sera from American and Swedish patients with AD caused some degree of immunolysis of synaptosomes compared with relatively few of the control sera, based on the three indices employed. The correlations between ChAT release, choline uptake and LDH release were statistically assessed by calculating Spearman rank correlation coefficients. The coefficient for the correlation between ChAT release and choline uptake inhibition for both American and Swedish sera taken together was -0.419 ( $p<0.05)$. Between ChAT and LDH release it was $0.409(p<0.05)$ and between choline uptake and LDH release it was -0.262 (not significant). The coefficients of determinacy for the significant correlations are about $17 \%$. Thus, for a given patient's serum, change from normal for one parameter was always accompanied by change in one or both of the other parameters but the linear relationship between the parameters accounts for only $17 \%$ of the variability in the data. The significance levels quoted are for a two tailed test.

\section{Activity of Sera from Patients with Other Forms of Dementia}

Sera from patients with atherosclerotic dementia, depression dementia, vascular dementia, and Parkinson's disease with dementia were tested in the immunolysis system against agematched control sera. These sera were ineffective in immunolysing rat brain synaptosomes as judged by release of soluble LDH, ChAT or $\mathrm{K}^{+}$(data not shown).

\section{Discussion}

The data presented here suggest that the sera from a group of American and Swedish patients with AD contain antibodies able to cause complement-mediated immunolysis of synaptosomes isolated from rat cerebral cortex and subsequently incubated at $37^{\circ} \mathrm{C}$. This immunolysis appeared to be principally of the cholinergic subpopulation of synaptosomes since soluble ChAT was released along with LDH, and high-affinity choline uptake was substantially reduced. In contrast, soluble GAD and $\mathrm{DBH}$, which are markers for GABAergic and noradrenergic synaptosomes respectively, were not released. It has previously been shown that specific complement-mediated immunolysis of cholinergic synaptosomes is caused by adding complement together with antibodies which recognise ChAT, $21,31,32$ whilst the GABAergic subpopulation can be lysed with antibodies recognising GAD plus complement, ${ }^{21}$ and noradrenergic terminals with DBH antibodies plus complement. ${ }^{37}$ Lysis of cholinergic synaptosomes with anti-ChAT released some $10 \%$ of total LDH present, ${ }^{21,31,32}$ which is close to the $10-15 \%$ of LDH released by the more active sera in the present study, and suggests that it is the cholinergic subpopulation which is being immunolysed by the Alzheimer patients' sera. Immunolysis of synaptosomes by antibodies and complement requires the corresponding antigen to be both present and accessible at the outer surface of the synaptosomes. In the present study the nature of the antigen allowing specific immunolysis of the cholinergic sub-populations by AD patients' sera remains uncertain. However, the effectiveness of ChAT antibodies in causing such immunolysis when added to brain synaptosomes, ${ }^{32}$ suggests that some form of ChAT itself could be the antigen in the membrane which allows the serum-mediated immunolysis to occur. This is

Table 2: Specificity of Immunolysis of Synaptosome Subfractions by Alzheimer Sera

\begin{tabular}{|c|c|c|c|c|c|c|c|c|c|}
\hline \multicolumn{10}{|c|}{ Release of Enzyme (\% of total released) } \\
\hline \multirow[t]{2}{*}{ Serum } & \multicolumn{3}{|c|}{ ChAT } & \multicolumn{3}{|c|}{ GAD } & \multicolumn{3}{|c|}{ DBH } \\
\hline & $S+C$ & $\mathbf{S}$ & $\mathrm{C}$ & $\mathrm{S}+\mathrm{C}$ & $\mathbf{S}$ & C & $S+C$ & $\mathbf{S}$ & $\mathbf{C}$ \\
\hline AA & $27 \pm 5.7$ & $0 \pm 0.3$ & $0 \pm 2.1$ & $1 \pm 0.8$ & $0 \pm 0.5$ & $1 \pm 0.9$ & $11 \pm 3.7$ & $6 \pm 2.0$ & $4 \pm 0.3$ \\
\hline $\mathrm{SA}$ & $12 \pm 2.7$ & $4 \pm 1.8$ & $2 \pm 3.0$ & $3 \pm 2.2$ & $1 \pm 0.2$ & $1 \pm 0.2$ & $\mathrm{~nm}$ & $\mathrm{~nm}$ & $\mathrm{~nm}$ \\
\hline $\mathrm{AC}$ & $2 \pm 0.9$ & $1 \pm 2.4$ & $3 \pm 1.9$ & $2 \pm 1.9$ & $4 \pm 1.4$ & $2 \pm 1.0$ & $\mathrm{~nm}$ & $\mathrm{~nm}$ & $\mathrm{~nm}$ \\
\hline
\end{tabular}

Rat cerebrocortical synaptosomes were incubated with the serum $(100 \mu \mathrm{l})$ for 2 hours at $37^{\circ} \mathrm{C}$ as described in Methods. Antibiotic (penicillin and streptomycin) were present (200 i.u./ml). AA, serum from American Alzheimer patient No. 2 of Figure 1; SA, serum from Swedish Alzheimer patient No. 7 of Figure 1; AC, American control serum No. 2 of Figure 1.

Values are mean $\pm \mathrm{SEM}$ of 3 determinations, $n \cdot m=$ not measured, $\mathrm{S}=$ serum alone, $\mathrm{C}=$ complement alone, $\mathrm{S}+\mathrm{C}=$ serum plus complement, added. All values were corrected for "no addition" controls. (Data from reference 1a). 
supported by our own studies ${ }^{33}$ and those of others 34-36 who have demonstrated the presence of membrane-bound ChAT in cortical synaptosomes.

Fillit et al 14 have reported that the patients' sera which bind to cholinergic neurons (see introduction), can partially inhibit ChAT activity in rat brain homogenates, and contain antibodies which recognize ChAT in immunoblots. Chapman et al13,18 found by immunoblotting and ELISA assays that immunoglobulins from sera of patients with AD bind to a specific antigen in the cell bodies and axons of Torpedo, the electric fish. This antigen has a molecular mass of 200 kilodaltons. Although soluble ChAT has a molecular weight of 68-72 kilodaltons, there is evidence for molecular aggregates of this enzyme molecule occurring in nerve-ending membranes with molecular masses of 230240 kilodaltons. ${ }^{35}$ In another study 16 antibodies in CSF from patients with $A D$ appeared to interact with cholinergic neurons in the rat CNS. These were detected immunocytochemically. The interaction was blocked by preincubation with antiserum to acetylcholine. However, others ${ }^{38}$ have reported that, employing an indirect immunofluorescence technique, they could detect no selective binding of antibodies in sera or CSF from patients with AD to neurons in frozen brain sections. Our own data, employing the very sensitive immunolysis technique, and the findings of these other workers ${ }^{14,16-18}$ taken together, suggest that autoimmune mechanisms, directed particularly at cholinergic neurons, might be involved in the pathogenesis of AD, either in the primary or secondary stages.

Itagaki et al $^{39}$ have detected large numbers of macrophages, reactive microglia and cells expressing leucocyte common antigen, as well as T-cytotoxic-suppressor and T-helper-inducer antigens, in temporal cortex and hippocampus of $\mathrm{AD}$, but not normal, brain tissue. Abnormally increased expression of HLADR antigens has also been detected in brains of patients with AD. 40.42 There is therefore evidence for both a cell-mediated (Tcell) and humoral (B-cell) autoimmune mechanism occurring in the brains of patients with $A D$.

It may be that the blood-brain barrier is breached in selected regions bearing plaques, where degenerating cholinergic and other nerve-endings, are accumulated. ${ }^{2}$ Such a breach has been reported.2,12,42 Antibodies recognising cholinergic nerve terminals, formed as a result, and reaching the blood via the CSF, could act in an autoimmune fashion to cause further plaque formation as cholinergic terminals are damaged by immunolysis. ${ }^{2}$ Evidence that autoimmune mechanisms involving antivascular antibodies may well play a key role in causing injury to the blood-brain barrier in AD has recently been published. ${ }^{15}$

Some of the non-cholinergic neurotransmitter changes seen in $A D^{1,4,43}$ may be the result of the primary cholinergic deficit. Thus glutamatergic pathways have recently been implicated, with losses of glutamate, glutamate high-affinity uptake, and of phosphate-activated glutaminase (PAG) occurring in the cerebral cortex and hypothalamus. $5,7,44$ Since both pyramidal neurons in the cortex and the cholinergic magnocellular neurons in the nucleus basalis show positive immunocytochemical staining for $\mathrm{PAG},{ }^{7}$ loss of this enzyme may reflect degeneration of both cortical neurons and afferent nerve endings. Since PAG and ChAT may coexist in the nucleus basalis neurons, 7,45 both enzymes would be affected by their loss.

\section{ACKNOWLEDGEMENTS}

This work was supported by an MRC (UK) Programme Grant, the Swedish Medical Research Council and the Medical Research Council of Swedish Life Insurance Companies. We acknowledge the extremely helpful consultations with Mrs. E.J. Snell, Lecturer in Statistics at Imperial College, about the statistical analysis of our data. We should also like to thank Barabara Cowen for typing the manuscript and Daniel Bradford for thoughtful technical assistance.

\section{REFERENCES}

1. Hardy J, Adolfsson R, Alafuzoff I, et al. Transmitter deficits in Alzheimer's disease. Neurochem Int 1985; 2: 545-63.

2. Hardy J, Mann DMA, Wester P, et al. An integrative hypothesis concerning the pathogenesis and progression of Alzheimer's disease. Neurobiol Aging 1986; 7: 489-502.

3. Sims NR, Bowen DM, Allen SJ, et al. Presynaptic cholinergic dysfunction in patients with dementia. J Neurochem 1983; 40: 503509.

4. Rossor MN, Emson PC, Mountjoy CQ, et al, Reduced amounts of immunoreactive somatostatin in the temporal cortex in senile dementia of the Alzheimer type. Neurosci Lett 1980; 20:373377.

5. Hardy J, Cowburn R, Barton A, et al. Region-specific loss of glutamate innervation in Alzheimer's disease. Neurosci Lett 1987; 73: $77-80$.

6. Greenamyre TJ, Penny JB, Young AB, et al. Alteration in L-glutamate binding in Alzheimer's and Huntingdon's diseases. Science 1985; 227: 1496-1499.

7. Akiyama H, McGeer PL, Itagaki S, et al. Loss of glutaminase-positive cortical neurons in Alzheimer's disease. Neurochem Res 1989; 14: 353-358.

8. Rosser MN, Svendsen C, Hunt SP, et al. The substantia innominata in Alzheimer's disease: An histochemical and biochemical study of cholinergic marker enzymes. Neurosci Lett 1982; 28: 217. 222.

9. Wilcock GK, Esiri MM, Bowen DM, et al. Alzheimer's disease: correlation of cortical choline acetyltransferase activity with the severity of dementia and histological abnormalities. J Neurol Sci 1982; 57: 407-417.

10. Wurtman RJ, Blusztajn JK, Maire J-C, et al. "Autocannibalism" of choline-containing membrane phospholipids in the pathogenesis of Alzheimer's disease - a hypothesis. Neurochem Int 1985; 7: 369-372.

11. Ishii T, Haga S. Immunoelectron microscopic localisation of immunoglobulins in amyloid fibrils of senile plaques. Acta Neuropathol 1976; 36: 243-249.

12. Alafuzoff I, Adolfsson R, Bucht G, et al. Albumin and immunoglobulin in plasma and cerebrospinal fluid, and bloodcerebrospinal fluid barrier function in patients with dementia of Alzheimer type and multi-infarct dementia. J Neurol Sci 1983; 60: 465-472.

13. Chapman J, Korczyn AD, Hareuveni M, et al. Antibodies to cholinergic cell bodies in Alzheimer's disease. In: Fisher A, Hanin I, Lachman C, eds. Alzheimer's and Parkinson's Diseases: Strategies for Research and Development. New York NY: Plenum Press, 1986: 329-336.

14. Fillit H, Luine VN, Reisberg B, et al. Studies of the specificity of antibrain antibodies in Alzheimer's disease. In: Hutton JT, Kenny AD, eds. Senile Dementia of the Alzheimer Type. New York NY: Alan R Liss Inc 1985: 307-318.

15. Fillit HM, Kemeny E, Luine V, et al. Antivascular antibodies in the sera of patients with senile dementia of the Alzheimer's type. J Gerontol 1987; 42: 180-184.

16. McRae-Degueurce A, Booj S, Haglid K, et al. Antibodies in cerebrospinal fluid of some Alzheimer disease patients recognise cholinergic neurons in the rat central nervous system. Proc Natl Acad Sci USA 1987; 84: $9214-9218$ 
17. Chang $\mathrm{CH}$, Teng EL, Henderson VW, et al. Clinical subtypes of dementia of the Alzheimer type. Neurology 1985; 35: 15441550.

18. Chapman J, Orit B, Korczyn AD, et al. Antibodies to cholinergic neurons in Alzheimer's disease. J Neurochem 1988; 51: 479485.

19. Foley P, Bradford HF, Docherty M, et al. Evidence for the presence of antibodies to cholinergic neurons in the serum of patients with Alzheimer's disease. J Neurol 1988; 235: 466-471.

20. Foley P, Bradford HF, Docherty M, et al. Evidence for the presence of antibodies to cholinergic neurons in the serum of patients with Alzheimer's disease. Biochem Soc Trans 1987; 15: 1034-1036.

21. Docherty M, Bradford HF, Wu J-Y, et al. Evidence for specific immunolysis of nerve terminals using antisera against choline acetyltransferase, glutamate decarboxylase and tyrosine hydroxylase. Brain Res 1985; 339: 105-113.

22. McKhann G, Drachman D, Folstein M, et al. Clinical diagnosis of Alzheimer's disease: Report of the NINCDS-ADRDA Work Group under the auspices of Department of Health and Human Services Task Force on Alzheimer's Disease. Neurology 1984; 34: 939-944.

23. Reisberg B, Ferris SH, De Leon MJ, et al. The Global Deterioration Scale for the assessment of primary degenerative dementia. Am J Psychiatry 1982; 139: 1136-1139.

24. Folstein MF, Folstein SE, McHugh PR, et al. "Mini-mental state": a practical method for grading the cognitive state of patients for the clinician. J Psychiatr Res 1975 12: 189-198.

25. American Psychiatric Association. Diagnostic and statistical manual of mental disorders. Washington 3rd ed 1980: 205-224.

26. Bradford HF, Bennett GW, Thomas AJ, et al. Depolarizing stimuli and the relase of physiologically active amino acids from suspensions of mammalian synaptosomes. J Neurochem 1973; 21: 495-505.

27. Fonnum F. Radio chemical microassays for the determination of choline acetyltransferase activities. Biochem J 1969; 115: 465472.

28. Vassault A. Lactate dehydrogense, the UV method. In: Bergmeyer HU, Bergmeyer J, Grabi M, eds. Methods of Enzymatic Analysis vol 3 Enzymes 1: Oxido Reductases, Transferases. Weinheim FRG: Verlay Cheme 1983: 118-136.

29. Joh TH, Ross RA, Reis DJ, et al. A simple and sensitive assay for dopamine-B-hydroxylase. Anal Biochem 1974; 62: 248-254.

30. Dixon WJ, ed. Biomedical Data Processing Program (BMDP), Revised printing. Berkley California: University of California Press: 1983.

31. Docherty M, Bradford HF, Anderton HB, et al. Lysis of cholinergic synaptosomes by an antiserum to choline acetyltransferase. Biochem Soc Trans 1982; 10: 368-369.
32. Docherty M, Bradford HF. A cell surface antigen of cholinergic nerve terminals recognized by antisera to choline acetyltransferase. Neurosci Lett 1986; 70: 234-238.

33. Docherty M, Bradford HF. Choline acetyltransferase in mammalian synaptosomes: evidence for an integral membrane-bound form. Neurochem Int 1988; 13: 119-127.

34. Eder-Colli L, Amato S, Froment Y, et al. Amphiphilic and hydrophobic forms of choline-0-acetyltransferase in cholinergic nerve-endings of the Torpedo. Neuroscience 1986; 19:275-287.

35. Badamachian M, Morris KJ, Caroll PT, et al. Immunological, isolectric, hydrophobic and molecular weight differences between soluble and ionically membrane-bound fractions of choline-0-acetyltransferase prepared from mouse and rat brain. Neurochem Int 1986; 9: 409-421.

36. Peng JH, McGeer PL, McGeer EG. Membrane-bound choline acetyltransferase from human brain: purification and properties. Neurochem Res 1986; 11: 959-971.

37. Docherty M, Bradford HF, Joh TH, et al. Specific lysis of noradrenergic synaptosomes by an antiserum to dopamine-B-hydroxylase. FEBS Lett 1986; 202: 37-40.

38. Watts $\mathrm{H}$, Kennedy PGE, Thomas M, et al. The significance of antineuronal antibodies in Alzheimer's disease. J Neuroimmunol 1981; 1: 107-116.

39. Itagaki S, McGeer PL, Akiyama $\mathrm{H}$, et al. Presence of T-cytotoxic suppressor and leucocyte common antigen positive cells in Alzheimer's disease brain tissue. Neurosci Lett 1988; $91: 259$. 264.

40. McGeer PL, Itagaki S, Tago $\mathrm{H}$, et al. Reactive microglia in patients with SDAT are positive for the histocomptability glycoprotein HLA-DR Neurosci Lett 1987; 79: 195-200.

41. Pouplard-Barthelaix A, Dubas F, Maher I, et al. Expression of HLA-DR (MHC class II molecules) in the brain: "in situ" demonstration of immunologic mechanisms in Alzheimer's disease (AD, SDAT). Neurology 1987; 37: (Suppl) 225.

42. Wisniewski HM, Kozlowski PB. Evidence for blood-brain barrier changes in senile dementia of Alzheimer's type (AD/SDAT): Alzheimer's disease, Down's syndrome and aging. Ann NY Acad Sci 1982; 386: 119-129.

43. Adolfsson R, Gottfries CG, Roos BE, et al. Changes in brain catecholamines in patients with dementia of Alzheimer type. Br J Psychiatry 1979; 135: 216-223.

44. Maragos WF, Greenamyre TJ, Penney JB, et al. Glutamate dysfunction in Alzheimer's disease: an hypothesis. TINS 1987; 10: 65-68.

45. Docherty M, Bradford HF, Wu J-Y. Co-release of glutamate and aspartate from cholinergic and GABAergic synaptosomes. Nature 1987; 330: 64-66. 